


\title{
Relato sobre el accionar violento en las montañas de Buenos Aires (Cauca) durante los últimos 55 años: un testimonio vivo de memoria*
}

\author{
Federico Guillermo Muñoz**
}

To no me voy, yo no me voy, yo no me voy, yo aqui me quedo, es la tierra donde nací, es la tierra donde crecí y aquí me muero.

("Yo no me voy", canción de José Édier Solis, habitante de Buenos Aires, Cauca)

* Este texto se basa fundamentalmente en el estudio de caso "Buenos Aires (Cauca): ancestrales costumbres, hechos de destierro y conflictos sociales, políticos, armados", que hace parte del trabajo de grado Reconstrucción de las trayectorias de vida de tres víctimas de destierro. Estudio de casos, elaborado para optar al título de magíster en Sociología.

** Magíster en Sociología de la Universidad del Valle. Miembro del grupo de investigación "Sujetos y Acciones Colectivas", adscrito a la Escuela de Trabajo Social y Desarrollo Humano de la misma universidad. Docente del programa de Sociología de la Universidad del Valle. Correo electrónico: fgmc25@yahoo.com 


\section{Breve análisis del contexto: a manera de preámbulo}

Para poder reflexionar sobre el esfuerzo que hicieron algunos mayores ${ }^{1}$ que habitan las montañas de Buenos Aires por recordar los diversos impactos de la violencia política, creemos conveniente comenzar con un análisis del contexto actual de conflicto armado, social y político que se vive en ese territorio, lo que en parte explica la continuidad de la violencia en esta codiciada zona.

En el cerro La Teta, donde convergen los hermanos municipios de Suárez y Buenos Aires, al norte del departamento del Cauca, la minería ha sido concebida por las comunidades indígenas y negras, que habitan este territorio desde hace muchos años, como un arte heredado ancestralmente. Recientemente, este oficio, en la mayoría de los casos desempeñado de manera artesanal, ha tenido que enfrentarse a una estrategia que podría caracterizarse como prácticas previas al despojo, a partir de la cuales se vienen presentando amenazas, señalamientos, desplazamientos forzados, asesinatos selectivos, desapariciones, masacres y otro tipo de acciones que, empíricamente se ha evidenciado, buscan el destierro de algunas comunidades mineras que han sustraído el oro durante varias generaciones, ya sea de la montaña o del río.

Esta situación viene sucediendo en medio de un contexto difícil para las comunidades: histórica presencia de las Fuerzas Armadas Revolucionarias de Colombia (Farc) en las montañas del norte del Cauca, reciente militarización de la vida social y comunitaria, múltiples infracciones al Derecho Internacional Humanitario (DIH) y violaciones de derechos humanos. Además, se ha venido gestando una reconfiguración narcoparamilitar, que se mezcla con la inusitada proliferación de cultivos de coca en las montañas de Buenos Aires, acompañada de una migración masiva de colonos provenientes de Putumayo y Nariño.

1 La comunidad afrocolombiana de Buenos Aires respetuosamente llama así a los adultos mayores. 
Actualmente se desarrolla un proyecto piloto de reparaciones colectivas propuesto por la Comisión Nacional de Reparación y Reconciliación (CNRR); se han realizado, además, algunos actos de reparación simbólica; ciertas organizaciones de víctimas y ONG que acompañan sus procesos efectuaron un ejercicio local de reconstrucción de la memoria, que buscó contrarrestar el olvido y recordar lo que pasó en tiempos de dominio y control territorial, social y político del Bloque Calima de las Autodefensas Unidas de Colombia (AUC). Durante el periodo 1999-2004, las AUC tuvieron un centro de operaciones en esta zona, de acuerdo con el testimonio de un líder de una organización conformada por víctimas, en su mayoría de la masacre del Naya:

Ellos inicialmente llegan a unas haciendas de acá del Valle, hablo de Timba, Valle, y al corregimiento de Robles; una finca del señor Pacho Herrera, narcotraficante, una finca que queda por allá en Barejonal, una finca La Ferreira. En esos sitios ellos se ubican, llegan ahí, empiezan a hacer inteligencia. La primera incursión como tal la hacen el 9 de junio [de 2000], cuando matan a dos personas, jóvenes de acá de la zona [...] Al otro día matan a cuatro personas en la vereda San Francisco. Pero antes de aparecerse en junio, ellos ya estaban aquí desde el mes de marzo, en esa finca. Ellos vinieron y allá tenían su centro militar de operaciones y toda esa infraestructura y logística. Y venían acá, pero de civil, o sea, venían a hacer inteligencia acá.

\section{El trabajo de campo que impulsó la escritura}

Los impactos que dejó en la zona el accionar violento de las AUG se remiten a la historia reciente, pero las comunidades de Buenos Aires han debido soportar diversas influencias armadas en los últimos 55 años. Durante el proceso del trabajo de campo de mi tesis de maestría tuve la oportunidad 
de participar en una actividad local de recuperación de la memoria ${ }^{2}$, llevada a cabo en la vereda La Alsacia, encaramada en las montañas bonaerenses, a partir de lo cual se intentó recordar y recrear algunos de esos acontecimientos violentos.

Poniendo en práctica la técnica de cartografía social, la comunidad participante construyó su versión de lo acontecido, a partir de la pregunta “¿cómo era Buenos Aires antes?”. De esta manera, mujeres, niñas y niños, jóvenes y mayores se dividieron en grupos de trabajo y reflexionaron sobre lo sucedido.

Las jornadas en La Alsacia fueron productivas, y los testimonios permitieron rememorar que el río Cauca antes no se "comía" la tierra, que es importante "recordar para vivir y vivir para resistir", que se han perdido algunas tradiciones, como las costumbres gastronómicas y la forma de tratar a las personas, porque la mayoría de jóvenes "andan en otra...". Ya casi nadie recuerda al gurre, animal silvestre y comestible que simboliza el robo de la dignidad y los procesos de resistencia, "porque logra sobrevivir a los cambios". Algunas personas han dejado a un lado las costumbres afroancestrales.

Una señora recordó cuando su abuela la llevaba al río a "minear" con una batea, a buscar oro. "Antes con 50 pesos uno llevaba bastante, hoy con 50.000 no lleva nada". Extrañaba la costumbre de moler maíz para hacer envueltos y cómo en el pasado mandaban a niños y niñas a misa sin zapatos, pero "ahora no salgo ni a la esquina sin chanclas", comentó una señora. "Ya se han olvidado las formas en que a uno lo curaban antes [...] En otros tiempos a las personas mayores se les hacía venia" (notas de campo, 9 de julio de 2009).

2 El ejercicio se enmarcó en el proyecto "Acompañamiento jurídico para la defensa de los derechos étnico- territoriales de las comunidades de Buenos Aires y Suárez (Cauca)", desarrollado entre la Asociación de Víctimas Renacer Siglo XXI, la Empresa Comunitaria Brisas del Río Aguablanca (Ecobra), la Corporación AVRE, la ONG Sembrar y el Proceso de Comunidades Negras (PCN) (Notas de campo en La Alsacia, 9 y 10 de julio de 2009). 
Uno de los mayores que participó en el ejercicio de rememoración fue don Miguel Carabalí Charrupí, cuyo testimonio impulsó la construcción de este documento. Él compartió con entusiasmo parte de su vida. Hemos podido recuperar una versión sobre las historias de violencia en la zona a través del relato de don Miguel, campesino de memoria prodigiosa, quien evocó su recuerdo de lo acontecido en estas montañas durante los últimos 55 años.

Nuestro interés por enfrentar críticamente el pasado radica en querer contribuir a esclarecer algunos hechos, revelar causas, autores, intencionalidades, sacar a la luz ciertas cuestiones que se quieren ocultar. En suma, analizarlo y reflexionarlo, para aumentar su comprensión, a través de testimonios que permitan el reconocimiento de las víctimas, es decir, que estas tengan la oportunidad de contar, narrar, testimoniar lo vivenciado, asumiéndose como sujetos activos, políticos, partícipes y propositivos (Barahona, González y Aguilar, 2008).

Don Miguel nació en Buenos Aires el 29 de septiembre de 1941, ha estado prácticamente toda su vida en este territorio y fue víctima del accionar paramilitar del Bloque Calima. En La Alsacia, a partir de la rememorización, profundizó en el origen de sonoros apellidos, muy comunes en Buenos Aires y Suárez, como Aponzá, Ocoró, Arará, Popó, Mina, Charrupí, Carabalí, y durante el ejercicio recordó el origen de uno de los suyos:

Pues mire, yo el "Charrupí” si no tengo claro el origen. Pero mi apellido "Carabalí" sí, lo tengo claro en todas las investigaciones que he hecho; yo investigué en el año 65 en Puerto Tejada, cuando pasó el problema de Nelson Mandela, que lo tenían preso, ¿cierto? Entonces en ese año había acabado yo de salir del Ejército, y estaba en Puerto Tejada y un señor que era fuerte de Puerto Tejada, que se llamaba Sabas Casarán, y un señor Marino Paz y Marino Viveros, uno que era médico [...]

Yo estaba parado un día conversando con un amigo, que habíamos salido del Ejército, en un almacén que le decían "El Barato". Y cuando 
pasaban ellos, uno de ellos me oyó conversando y le dio ganas de mirarme, y ahí mismo me llamó y me dijo que fuera donde él, y yo pues medio sorprendido, y me dijo: "No, venga, que no le voy a decir nada malo". Y entonces yo fui y me dijo: "Vea, nosotros vamos a tener una reunión ahorita en la casa del doctor Marino Paz, y lo necesitamos a usted". Y le dije: "No, pero es que yo no conozco...”. Y él me dijo: "No, camine de una vez".

Y me llevaron allá, y ese día era pa’ solidarizarnos con la causa de Nelson Mandela [...] Y me dijeron: "Usted como joven tiene que ser el primer joven negro que se solidarice con la causa de Nelson Mandela". Y ahí fue que ya dijeron: "A usted por su apellido le toca". Y entonces yo les pregunté que de dónde venía mi apellido, y me dijeron que era nigeriano (entrevista con don Miguel Carabalí Charrupí, La Alsacia, 10 de julio de 2009).

Así como don Miguel recordó, hizo memoria y reconstruyó historia, también lo hicieron otros mayores afrocolombianos, como don Ananías, que lamentó la incursión de los actores armados en la zona y los falsos rumores que difundió el Bloque Calima en diciembre de 2000, cuando "se vaciaron las montañas", logrando su objetivo de propagar el miedo y desterrar a las comunidades. También don Carlino declamó una copla alusiva a las mujeres, siguió de cerca la conversación que tuve con don Miguel, le cubrió algunos olvidos, pero no logró recordar mucho. De pronto a veces es mejor olvidar.

La memoria del pasado aflora ocasionalmente e invade el espacio social donde se recuerda, permitiendo incorporarlo, elaborarlo, procesarlo, trabajarlo, darle un lugar, lo que implica pensar y analizar las presencias y sentidos de un pasado que se quiere y puede conservar. Entonces la memoria se revisa y se resignifica en periodos siguientes a los hechos victimizantes, logrando de esta manera transitarla, controvertirla y, en algunos casos, tener una construcción conjunta del pasado (Jelin, 2004). 


\section{¿Qué sabemos acerca de los mayores que habitan las montañas de Buenos Aires?}

Muchos hacen parte de la comunidad afrocolombiana, lo que implica un modo particular de asumir el territorio, la vida en comunidad, el comportamiento en sociedad. Sus costumbres han sido heredadas y son inculcadas a las generaciones siguientes: valorar el territorio, trabajar la tierra, respetar a la comunidad vecina.

Los moradores han pasado gran parte de su existencia en ese territorio, lo han caminado, recorrido y cultivado, como campesinos que en su gran mayoría son, aunque otros se han dedicado a la minería, oficio de gran relevancia para la idiosincrasia del territorio que comprende los municipios de Buenos Aires y Suárez: la consideran y asumen como un arte heredado ancestralmente ${ }^{3}$. En ciertos casos, sobre todo en tiempos pasados, se mezclaba agricultura y minería como formas de subsistencia.

Los mayores son respetados, reconocidos socialmente por la comunidad afrocolombiana y generalmente se les escucha y se les hace caso a sus consejos. Al conversar con ellos, se aprende. Irradian una energía de tranquilidad; pareciese que les sobrara paciencia. Encarnan sabiduría en palabra, forma de afrontar la vida y convivencia en sociedad. Están abiertos a transmitir sus conocimientos, compartir sus historias, recordar con generosidad, como lo hizo don Miguel en su relato sobre la violencia en Suárez y Buenos Aires durante los últimos 55 años, que consideramos un testimonio vivo que podría constituirse en el comienzo de un proceso de recuperación de la memoria.

3 La persona víctima del destierro en Buenos Aires, que compartió su historia para construir el estudio de caso mencionado, afirmó: “[...] El tema de la minería, que es otro arte. Desde que nos arrancaron de África fueron unos al tema de la agricultura y otros al tema de la minería [...] Suárez era corregimiento de Buenos Aires hasta antes del noventa. A través de los siglos hemos venido acá en la práctica tradicional del manejo de la minería de una forma artesanal. Hay un arte en la explotación de minería, que se llama "canalones", que es única en Buenos Aires y que se utilizó en épocas de la Colonia acá, cuando estaban los españoles. Una metodología de explotación de la minería de una manera artesanal, una tecnología única y muy efectiva". 
Un comienzo, porque su testimonio podría ser complementado con el de otros mayores, como don Carlino y don Ananías, que también participaron en el ejercicio de recuperación de la memoria en La Alsacia. Lo que sí nos queda claro es que falta mucho por saber sobre los mayores; es bastante lo que podríamos conocer, pero el tiempo pasa, los años siguen sumando achaques, menguando la energía, afectando la salud, y no sabemos si disminuyendo la actitud y la motivación por recordar.

Los esfuerzos por recordar colectivamente involucran agentes sociales que buscan confrontar las memorias oficiales, dominantes, hegemónicas, que en ocasiones manipulan lo sucedido y tienen intenciones homogeneizadoras para posicionar una sola versión de lo vivido durante periodos de violaciones masivas a los derechos humanos.

Frente a políticas, intenciones y estrategias que le apuestan al olvido, existen memorias alternativas, en contracorriente a lo establecido, que cuestionan las versiones oficiales. Quienes las impulsan son considerados por Jelin (2004) como agentes de la memoria, que le dan un uso político y público, la apropian, reivindican, luchan por protegerla, preservarla, difundirla.

Es entonces cuando las víctimas pueden desplegar contramemorias que hagan contrapeso a las políticas de olvido; contramemorias que resistan a la "ocultación deliberada e inconsciente". Pero estas posturas en contra del olvido no pueden confundirse con una memoria particular que se imponga como memoria social; la reflexión debe girar en torno a cómo las memorias colectivas están íntimamente relacionadas con los grupos sociales que las "producen” (Sánchez, 2003).

Quien promueve las memorias alternativas, las contramemorias, puede ser considerado como un emprendedor de la memoria:

Se involucra personalmente en su proyecto, pero también compromete a otros, generando participación y una tarea organizada de carácter colectivo [...] Es un generador de proyectos, de nuevas ideas y expresiones, 
de creatividad -más que de repeticiones-. La noción remite también a la existencia de una organización social ligada al proyecto de memoria [...] Pretenden el reconocimiento social y de legitimidad política de una (su) versión o narrativa del pasado. Y que también se ocupan y preocupan por mantener visible y activa la atención social y política sobre su emprendimiento (Jelin, 2004, pp. 48-49).

\section{¿Qué nos relató un mayor, basado en el recuerdo y el olvido, sobre la violencia en Buenos Aires durante los últimos 55 años?}

Don Miguel Carabalí Charrupí ha vivido prácticamente toda su vida en la vereda Materón, perteneciente al corregimiento El Porvenir. Ahí tiene su vivienda y ha cultivado la tierra, lo que le ha permitido sacar adelante a su familia y ser considerado como un campesino trabajador y honesto, que es respetado por la comunidad afrocolombiana. Tiene 70 años, pero por su apariencia física pareciera de menos edad. Siempre lleva puesto un sombrero y nunca lo desampara un reloj grande en su mano izquierda.

El relato que recuperamos surgió de una entrevista semiestructurada, realizada en la vereda La Alsacia el 10 de julio de 2009, y como todos los testimonios, expresa una memoria fragmentaria, ciertas lagunas y algunos olvidos, que se manifiestan en frases como "se me viene aquí y se me vuelve y se me va... Bueno, cuando me acuerde le digo".

Cada víctima tiene derecho a reconstruir lo que le sucedió, a no ser partícipe de la estrategia que con intencionalidad pretende "pasar la página" e invita a olvidar; empero, el olvido es una posibilidad, en tanto puede darse una fracasada experiencia de la memoria. Esto puede ocurrir ya que la memoria es fragmentaria, el ejercicio de recordar es una experiencia de rememoración que puede tener huecos, baches, vacíos, olvidos y omisiones. Incluso, en algunos casos la memoria puede tener exageraciones o, en un contexto donde esta tenga alguna intencionalidad, se puede dar 
una sobreinterpretación, como ha sucedido con el caso del holocausto Nazi (Sarlo, 2006).

La conversación con don Miguel se concentró en recuperar historias vividas, anécdotas recordadas e impresiones sentidas sobre la presencia e influencia de muy diversas expresiones armadas que hicieron presencia en las montañas de Buenos Aires durante los últimos 55 años. Él comenzó remontándose hasta el primer recuerdo de esas influencias violentas:

Pues mire, en Buenos Aires, cuando nos criamos nosotros, simplemente no había nada de sectores armados, no se conocía nada. Cuando empezaron a resultar fue en el año 54 o 55, por ahí en el 55; empezó a salir una gente a la que le decían "los salteadores de caminos"... Don Carlino, ¿usted recuerda?4

Los salteadores salían a saltear a la gente en los caminos, para robarles las cosas. Entonces salían los salteadores, que era lo que uno conocía como gente mala.

De acuerdo con lo evocado por don Miguel, fue a mediados de los años cincuenta cuando llegaron los primeros armados, que él primero llama "bandoleros" y luego "chusmeros". A partir de una fragmentada anécdota recrea lo vivenciado en ese momento, más de 50 años atrás:

Bueno, en el año... por ahí en el año 57 se conoció de los primeros armados, que les llamaban los "chusmeros". Se dijo que llegaban unos chusmeros a San Francisco. Entonces en ese tiempo toda la gente salía, venía a trabajar a Buenos Aires, a sus montañas, que esto lo llamábamos "la montaña".

4 Durante la conversación, don Carlino, otro mayor afrocolombiano, campesino de la zona, de más edad que don Miguel, estuvo escuchando atentamente el testimonio, y aunque no participó activamente, creemos que realizó un ejercicio de recordar lo sucedido, ya que en algunas oportunidades intentó complementar el testimonio de don Miguel. 
Era un lunes, había una señora... El apellido se me olvida; en todo caso, el marido sí se llamaba, este... Enrique Lugo. Ellos eran mineros, habían hecho unas minas en el alto San Francisco, y esos salteadores... esos chusmeros habían venido a asaltar la finca, la mina. Entonces ella por allá sola, ella era una mujer muy buena; a todos los campesinos, cuando pasaban por ahí, ella les daba su plato de mazamorra, aguapanela, y todo el mundo le llevaba plátano, yuca; ella no compraba nada de revuelto.

Entonces cuando ella gritó, toda la gente se paró a ver qué era. Ella pidió auxilio y todo mundo corrió. Ese día salía gente de una parte y de otra y encerraron a esa gente, y esa gente corra y corra. Eran tres, hasta que cayeron a una quebrada que se llama Charco Azul; y allá se enterraron por esa quebrada y eso le prendieron candela a esa loma, y los tipos se metían a los pozos donde veían que la candela no... Pero allí los sacaron, y en ese tiempo pues no había carro, no había nada, sino todo era el tren, que pasaba por San Francisco. Entonces llegaron y los amarraron y fueron y se los entregaron a la PM, que era la que andaba en el tren, los soldados, que les decían la PM. Y se los entregaron a ellos y ellos se los llevaron. Ese fue el primer accidente armado que se sintió en Buenos Aires.

Considera don Miguel que fue en 1958 cuando por las montañas pasó el que considera el primer "terrorista", que se hacía llamar "Plumas Verdes", asesinado en la estación de Policía de Timba, en la parte plana del municipio. También evocó la presencia en la zona del "Capitán Rayo", militante del partido Liberal y quien asesinó a cuatro conservadores en un recorrido que lo llevó desde Materón hasta el casco urbano de Buenos Aires. Como recuerda don Miguel, "en ese tiempo mataban más era por política, era el partido Liberal y el partido Conservador". Posteriormente llegó una estructura armada más organizada, que la gente conocía como "la Policía Cholavita". 
Tras breves alusiones a las guerrillas liberales de los Llanos, donde mencionó a Guadalupe Salcedo y a "un negro chocoano" que llamaban "La Osa", dio un salto a otro tipo de expresiones armadas, más enmarcadas en el contexto de conflicto armado, social y político, como la guerrilla de las FARC y la Coordinadora Nacional Guerrillera, que se caracterizaban por su clandestinidad, ya que "...ellos entraban y salían, pero uno no los veía [...]No se dejaban ver, uno sentía apenas por la noche los perros latir".

La guerrilla de las FARC entró acá casi como en el año... como en el año 72, del 72 al 73. Porque el primer comandante que entró acá, llamado Daniel, a ese lo mataron en Munchique; él salió del Naya, él iba con tres compañeros y ahí unos policías de Buenos Aires lo mataron, ahí en Munchique. Él entró con trece... o me parece que era con siete hombres.

Luego da un salto a los años ochenta, cuando "ya se sintió el impacto propiamente de la guerrilla acá, fue cuando la Coordinadora...". Recuerda que fue en ese momento cuando se agudizaron los enfrentamientos:

Fue fuerte, fue el primer impacto más fuerte que hemos tenido en toda la zona; conocimos los aviones bombardeando [...] Era por ahí entre 1985 y 86. Porque nosotros no sabíamos cómo un avión bombardeaba una zona. Y ese día inclusive fue que mataron a un guerrillero que le decían "Alfaro Díaz". Y en esa ocasión, de esa montaña uno oía que llegaba esa avioneta lanzando bombas; entraban como seis avionetas a bombardear.

Comenzaron entonces a vivirse profundos cambios en la cotidianidad de la montaña:

Ahí se empezó... Uno que no ha sido acostumbrado a esas cosas, ya empieza a sentir miedo, ya no se desplaza pa' donde quiera; porque nosotros acostumbrábamos ir de ahí de mi vereda donde yo más 
permanecía, que era Materón, nosotros nos íbamos de ahí a la una de la mañana para Buenos Aires con las cargas.

Y uno a la hora que quisiera cargar, después de que tuviera el tiempo bueno y bonita luna, uno decía "vámonos con la luna, por las trochas". Y uno cargaba sus bestias y salía por las trochas y tranquilo llegaba a su casa. Pero cuando ya empezó a haber esa descomposición, ya la gente no pudo volver a salir, ya todo mundo le tenía miedo a la salida [...], ya la gente empezó a sentir temores, empezó a tener temor por sus hijos, que de pronto fueran a quitárselos.

Otra guerrilla con influencia en los ochenta fue la del M-19, que tuvo amplia presencia en el Cauca y que en Buenos Aires intentó "regular" algunos conflictos sociales y familiares:

El M-19 tuvo todo esto. Inclusive, aquí estuvo este Rosemberg Pabón, y acá, en esta zona, estuvo este Andrés Almarales y estuvo este otro... Claro que Andrés Almarales no duró mucho. Pero acá estuvo Rosemberg Pabón y otro, no me acuerdo [...] Como siempre hacen los grupos, cuando llegan siembran el terror a todo mundo, queriendo acabar con todo, arrasar con todo. Pero después ellos no..., ya se apaciguaron con la gente. El que robaba era el que lo mataban. Claro que hicieron matar mucha gente.

Porque por lo menos acá había unas mujeres muy... ¿cómo le dijera?, chismosas, que llegaban y no les caía bien una persona y por cualquier cosita ahí mismo le informaban, y en ese tiempo, desde que ellas informaban, los mataban, sin preguntar. Entonces con los tiempos ellos empezaron a mirar que habían cometido unos errores y ya llamaron a reunión. Y entonces ahí ya fue cuando comenzaron a decir que si una persona iba a denunciar a otra persona, y que no tuvieran pruebas de lo que había hecho, entonces los mataban a todos dos. Y ahí fue cuando ya empezaron bochinches y matazones. 
Tras la desaparición de la Coordinadora y la reinserción del M-19, en Buenos Aires solo las Farc tuvieron una presencia sostenida. Entre 1977 y 1978, don Miguel fue requisado en un retén por unos hombres armados, "supuestamente soldados", en lo que pareciera ser, según sus recuerdos anecdóticos, una de las primeras acciones de grupos paramilitares en la zona. Lo que sí recuerda con claridad es la versión sobre la llegada de los paramilitares del Bloque Calima en el año 2000:

Eso sí borró todo, eso sí borró todo, porque le digo que la guerrilla sí causó impacto fuerte, esos sí crearon un impacto demasiado... Eso se manifestó en que la gente ya empezó a sufrir mucho, porque le mataban sus hijos, sus hermanos, sus sobrinos, sus primos, sus amigos, todos, mejor dicho. Y el trato, un trato tan cruel...

Inclusive hubo una ocasión, ahí en Timba, yo venía en la chiva de El Ceral, y había un comandante de esos haciendo un retén en la salida de Timba. Y empezó: "Que bajen todas esas remesas". Y no le dejaban subir las remesas a la gente. "Bajen todas esas remesas, que eso es pa' esos hijuetantas yo no sé qué”. Y entonces dije: “¡Huy!, yo pensé que todavía vivíamos en Colombia".

Pero le cuento que yo no sé... estuve con Dios encima, que ese hombre no me mató porque no... Pero qué hombre para sentirse tan ofendido, y me decía: "Sí, en Colombia sí vivimos, pero no es tan democrática como la cree usted".

\section{Reflexión final: lo que dejó el ejercicio de recuperación de la memoria en La Alsacia}

Actualmente se vive en Buenos Aires un contexto complicado de reconfiguración narcoparamilitar y procesos de revictimización, lo que dificulta la intención de recordar la violencia soportada durante tantos años y 
complejiza la postura de exigir y reivindicar los derechos a la verdad, justicia y reparación.

El énfasis que se ha hecho en la posibilidad de recuperar un relato que contribuya a la recuperación de la memoria de lo sucedido en Buenos Aires no es una apología a los mayores; nuestra intención no es "endiosarlos" ni idealizarlos. Sentimos admiración hacia ellos y respeto por su testimonio, pero somos conscientes de que tienen defectos, cambios sustanciales en su temperamento y en algunas ocasiones quieren tener la razón a como dé lugar.

De acuerdo con lo que hemos reflexionado sobre la memoria a partir del estudio de enfoques como el de Halbwachs, creemos que está hecha de los recuerdos alojados en la dimensión interior de quien evoca; sin embargo, en un contexto mediado por el contacto entre la sociedad y "nosotros" se gesta un apoyo en algunos marcos (tiempos y espacios) de la memoria colectiva. Es difícil creer que los recuerdos puedan ser considerados como puramente interiores, que solo se conserven en la memoria individual, ya que de alguna manera reproducen la percepción colectiva de lo sucedido, integrando nociones y lógicas. Así, esas imágenes individuales que subsisten, persisten y resisten en la conciencia, paulatinamente reaparecen y forman el recuerdo. El pasado no se conserva intacto en las memorias individuales, al transitar por diferentes experiencias e individuos. De esta manera, el contexto social en el que se desenvuelve quien recuerda contribuye a comprender, evocar, mantener vigente o reconstruir momentos del pasado:

Sin lugar a dudas, resulta difícil modificar el presente, ¿pero no lo es mucho más, con ciertas reservas, transformar la imagen del pasado, que existe del mismo modo, virtualmente al menos, en el presente, dado que la sociedad siempre conserva en su pensamiento los marcos de su memoria (Halbwachs, 2004, p. 337). 
Quien evoca recuerdos, apoyándose en marcos de la memoria social, lo hare en el marco de un grupo social. Podríamos proponer entonces, en el caso de los mayores de Buenos Aires, que su memoria tiene una función colectiva y social (Halbwachs, 2004).

Creemos que un ejercicio de rememoración colectiva, como el que se llevó a cabo en La Alsacia, permite construir acuerdos, recordar en conjunto, divertirse recordando (risas, bromas pesadas, "montadera", "recocha"). En esta situación, entre mujeres y hombres emergen vínculos familiares y sociales de antaño, que los y las unen, las y los fortalecen como comunidad afrocolombiana.

Los mayores comparten su proceso de rememorar sobre la violencia en su territorio, en tanto su memoria es generosa y se reconoce el esfuerzo que hicieron por recordar lo sucedido: se resitúan en los territorios caminados, que han hecho parte de su biografía y donde han vivido; se recuperan sus relatos y testimonios, aquellas historias por contar, personajes sin nombrar, situaciones experimentadas, hechos acontecidos; en suma, se habla del territorio con propiedad.

Tal como lo afirmamos, el ejercicio de cartografía social con los mayores de Buenos Aires y la entrevista realizada a don Miguel pueden ser insumos para comenzar un proceso de recuperación de la memoria sobre la violencia en esta zona. Creemos posible y viable retomar el contacto con los mayores, a quienes postulamos como "emprendedores de la memoria".

Un buen comienzo pudo haber sido el reencuentro con don Carlino, durante la Conmemoración de los 10 Años de la Masacre del Naya, un acto de reparación simbólica que se llevó a cabo el 11 de abril de 2011, en lo que alguna vez fue la plaza de mercado de Timba (Cauca). Aquel día lo noté disminuido y cansado, su salud estaba bastante precaria y no aprecié la energía que desplegó durante el ejercicio de recuperación de la memoria en La Alsacia. Le propuse que realizáramos una actividad de rememoración colectiva, junto con don Miguel y don Ananías, que profundizara en los 
hechos de violencia vividos en el territorio durante los últimos 55 años. La idea le sonó y se mostró dispuesto a participar.

El reto ahora es seguir apoyando estos incipientes procesos que se impulsan desde las comunidades locales, al igual que contribuir, de alguna manera, a recuperar las versiones de lo sucedido, desde las voces de las personas que lo vivieron, como es el caso de algunos mayores que habitan las montañas de Buenos Aires.

\section{Referencias}

Barahona, A., González-Enríquez, C. y Aguilar, P. (2008). La política de la memoria: justicia transicional en sociedades en proceso de democratización. Romero, M. (Ed.). Verdad, memoria y reconstrucción. Estudios de caso y análisis comparado (pp. 169-223). Bogotá: Centro Internacional para la Justicia Transicional.

Halbwachs, M. (2004). Los marcos sociales de la memoria. Caracas: Anthropos.

Jelin, E. (2002). Las luchas políticas por la memoria. En Los trabajos de la memoria (pp. 39-62). Madrid: Siglo XXI - Social Science Research Council.

Sánchez, G. (2003). Guerra, memoria e historia. Bogotá: Instituto Colombiano de Antropología e Historia.

Sarlo, B. (2006). Posmemoria, reconstrucciones. En Tiempo pasado. Cultura de la memoria y giro subjetivo. Una discusión (pp. 125-157). México: Siglo XXI. 